\title{
Relationship Between World Heritage and Residents in Post Application Period: A Case Study from Xi'an, China
}

\author{
Yi Yu ${ }^{1}$ and Qian Wang ${ }^{2, *}$ \\ ${ }^{1}$ School of Cultural Heritage, Northwest University, Xi'an, Shannxi 710119, China \\ ${ }^{2}$ Institute of Silk Road Studies, Northwest University, Xi'an, Shannxi 710119, China \\ *Corresponding author. Email: 452379374@qq.com
}

\begin{abstract}
This study aims to improve the level of sustainable development of sites with a large population that has been successfully listed as World Heritage. In order to meet this purpose, this paper studied the status quo of the Han Chang'an City Site, a typical representative of such sites. A questionnaire survey was conducted among the residents of the site area and those who had moved out of the site area due to the application for World Heritage. The results indicate that the relationship between the residents and the site is unsustainable. The relocated residents are also generally dissatisfied with their current situation. Based on these results, this paper puts forward some corresponding solutions.
\end{abstract}

Keywords: World Heritage; Han Chang'an City; Residents; Protection; Tourism Development

\section{INTRODUCTION}

In June 2014, the "Silk Road: the road network of Chang'an-Tianshan corridor" was successfully declared as a World Heritage Site. The Site of Weiyang Palace in Chang'an City of Western Han Dynasty was officially listed as the starting point of the Silk Road in the World Heritage List. However, the success of this application is not the end of heritage protection. Becoming a World Heritage site generates both opportunities and challenges. The Han Chang'an city site has a close relationship with its residents. Thousands of villagers live in this large area, which generate a series of affairs, such as heritage management, cultural tourism, environmental protection and so on. However, the arduous process and success of applying for the world heritage has made a great change in the relationship between the site and its residents. Therefore, a study on protection and development of cultural heritage from the perspective of the residents has an important significance.

Some scholars have done some related research before. In the aspect of heritage protection, Zhang Zuqun and other scholars analyzed the destruction factors of the Han Chang' an city site[1]. Based on the strategy of sustainable development, Quan Dongji put forward some countermeasures for the protection and development of the Han Chang'an City[2]. Fan Haiqiang and others put forward a new idea of establishing a "site protection exhibition area + construction control area + cultural industrial park" in the Han Chang'an City[3]. The group of Chen Wenliang investigated the internal residents of the two major sites of Han Chang'an city and Yongcheng respectively, and pointed out that the methods of harmonious symbiosis between the site and the inhabitants should be actively explored[4]. Zhang Hong studied the relocation work of the residents in the Han Chang'an City, and put forward to set up protection and Development Management Committee and raise funds for relocation[5]. In general, the above-mentioned study of the Han Chang'an city is less concerned with the residents inside the site area, and the only research on the residents of this site is before the successful application of the World Heritage lacking follow-up investigation and discussion on the current situation of this site after the application of the World Heritage.

\section{SITE PROFILE AND RESEARCH METHODS}

\subsection{General Situation of the Area}

Han Chang'an City site locates in the northwest of Xi' an City, Shaanxi Province, which is the political, economic and cultural center of the West Han Dynasty. At present, the site area is well preserved. It is one of the earliest and most well preserved ancient city sites in China[6].

In the process of World Heritage nomination, the protection and utilization of Han Chang'an city site has been paid more and more attention by government and the public. To support this application, the authorities set up a Han Chang' an City National Site Protection Zone for the overall management and spent a large amount of money on residents relocation and environment improvement. More than 50,000 residents and more than 1,000 enterprises and institutions have successfully moved out from the reserve 
area (As shown in Figure 1, the two satellite remote sensing photos were taken before and after the application for the Silk Road's designation as a World Heritage site. The left figure shows that there are many villages, enterprises and institutions in this site area before the demolition. In the right figure, in the lower left corner of the site, the buildings in the core area of Weiyang Palace have been demolished, and only a large amount of yellow homestead, the Cultural Administration Office, the Special Administrative Committee and other scattered buildings are left. The pattern of two horizontal and one vertical roads of Weiyang palace has also been restored); the relevant departments have carried out large-scale greening

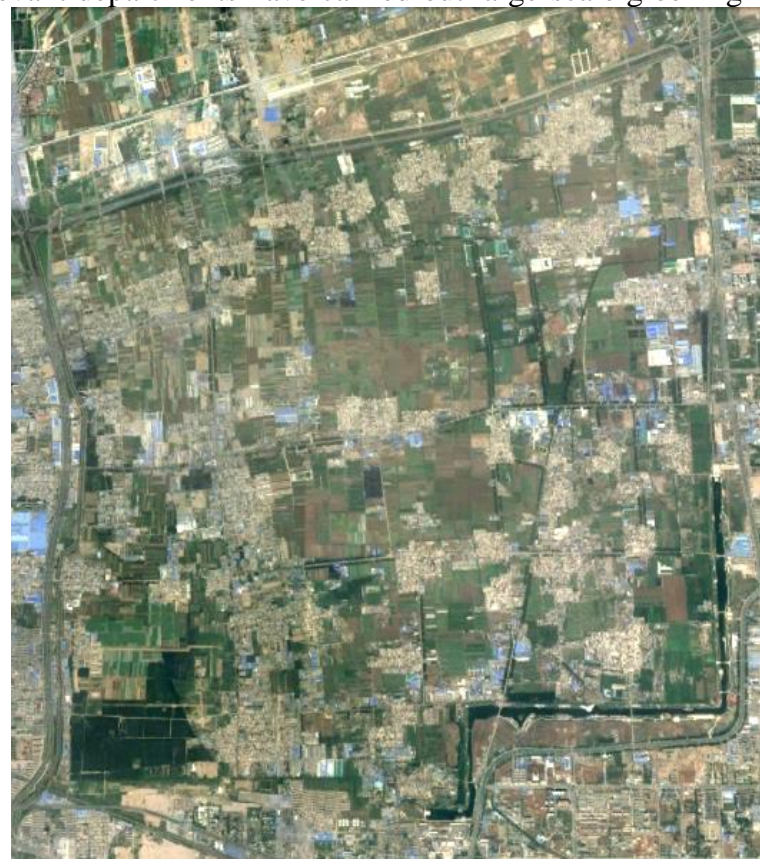

projects in the site area, and added 90,000 acres green space[7] .

At the same time, the relevant departments have also built several new protection and display facilities, such as a new exhibition hall next to the former palace site and wooden walkways and platforms built on the former temple site[8]. The Xi'an Gate site has been displayed by means of rammed earth features combined with window display. For the sites, such as government offices, Shaofu, Jiaofangdian, etc., the original sites have been backfilled and the archaeological excavations have been reproduced after covering the earth[9].

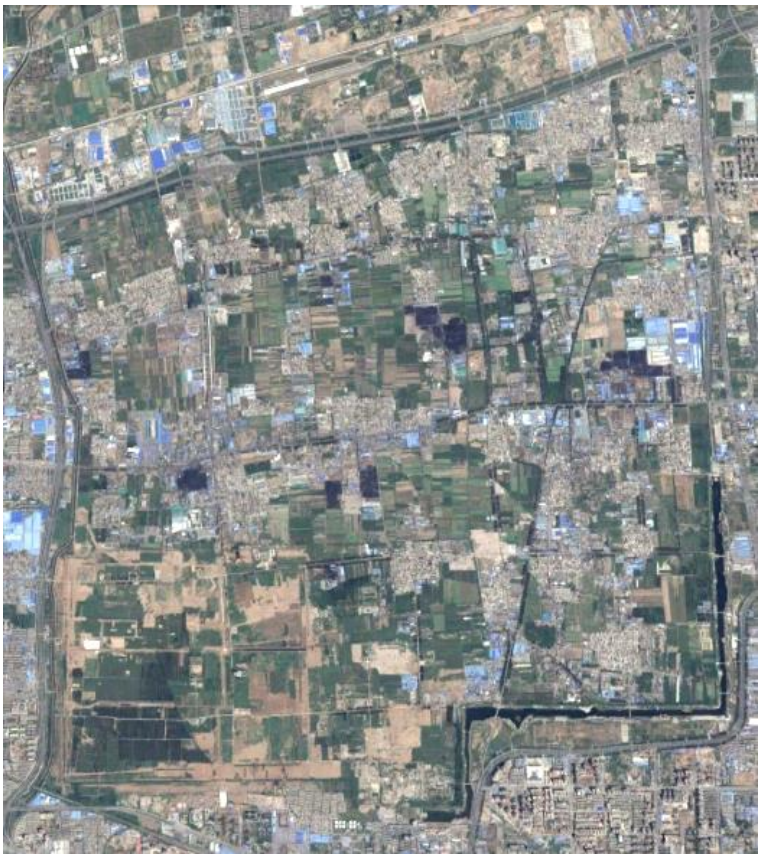

Figure 1. Comparison of the Han Chang'an City Site before and after the application (the left picture shows satellite photo taken in June 2012 and the right picture shows satellite photo taken in August 2013)

\subsection{Research Methods and Data Sources}

Through interviews with the management of the special site of Han Chang'an City and the questionnaire survey of the residents, this article studied on the attitude and opinions of residents on the protection and development of the site. The SSPS19.0 software was used to carry out statistical analysis and combined with the recovered questionnaire.

A total of 800 questionnaires were distributed and 701 were valid with an effective recovery rate of $87.6 \%$. To study on the current living conditions of the relocated people and their views on the application work, 200 questionnaires were distributed and 164 were valid with an effective recovery rate of $82 \%$.

\section{THE PRESENT RELATIONSHIP BETWEEN THE RUINS AND THEIR RESIDENTS}

\subsection{Conflict between the Site and its Residents}

The results of the survey show that the relationship between the site and its residents who still live in the site area is not optimistic. It could be summed up in the following aspects:

\subsubsection{Low income and limited development of residents}

Local economic development is limited by the site protection policies. Most of the villagers can only use the 
primary industry as their basic means of livelihood (nearly 70 percent of the residents surveyed fill in the occupation column for farmers). According to this investigation, more than half of the residents interviewed earn less than 1000 yuan per month. More than 73 percent of those surveyed said the site protection policies effect their life and feel negative to protection policies(as shown in the figure 2). Low income is an important factor which influence the relationship between the site and its residents.

\subsubsection{Environmental problems and infrastructure backwardness}

In recent years, with the rapid development of social economy, the surrounding area of the site has developed rapidly and the urban environment has changed with each passing day[10]. Nowadays, Han Chang'an City site is surrounded by urban built-up areas, which make it become a veritable "village in the city "[11]. According to this survey, the environment of Hancheng Lake was obviously improved after protection, but the nearby village environment tends worse.

In addition, for the need of protection, the construction of relevant municipal facilities in the site area is greatly constrained. 62 percent of the surveyed residents expressed dissatisfaction with the infrastructure in the existing place of residence. Some villagers still use well water. Road facilities are aged without plan. Water accumulation is serious in many sections of the road, which affect the safety of pedestrian vehicles.

\subsubsection{The existing management system has led to poor communication}

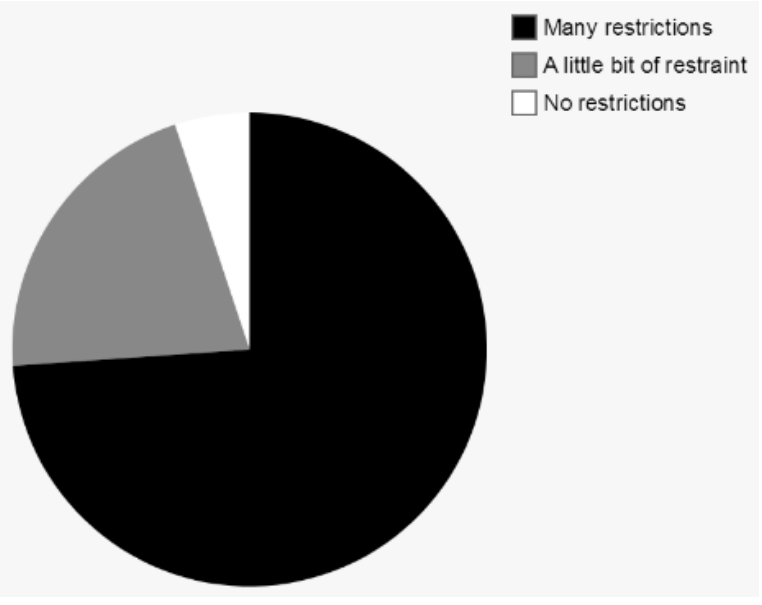

Figure 2. Does cultural heritage protection place restrictions on you?
In order to solve the internal affairs, government set up the Han Chang' an city site special zone. However, in view of the current operation, the Special Administrative Committee has only the authority to approve the land in the site area, while the administrative power of the villages in the area is still owned by the local government, so there is a situation of management confusion and mutual wrangling. As a result, although the willingness of the residents of the site area to participate in site management is not low (nearly two-thirds of the respondents expressed their willingness to participate in site management and decision-making, as shown in the figure 3), it is difficult to find suitable ways to participate.

\subsubsection{Successful application for the World Heritage failed to bring more benefits to local residents}

Survey results show that more than $70 \%$ of the respondents believe that the conservation and utilization of the site has not effectively improved their life. This result may be caused by the fact that all the villages that have not been relocated are located outside the core area of the application——Weiyang Palace site area, and the existing conservation and utilization of the site is mainly concentrated in the Weiyang Palace area, because of which the residents of other site areas lack of attention. Secondly, because the relatively small number of visitors soon after the site park was built, it is difficult to promote the development of the related industries in the surrounding villages. In addition, the management committee of the Special Administrative Region has not employed more local villagers in the site management and construction project, and has not been able to bring more employment opportunities to the local people.

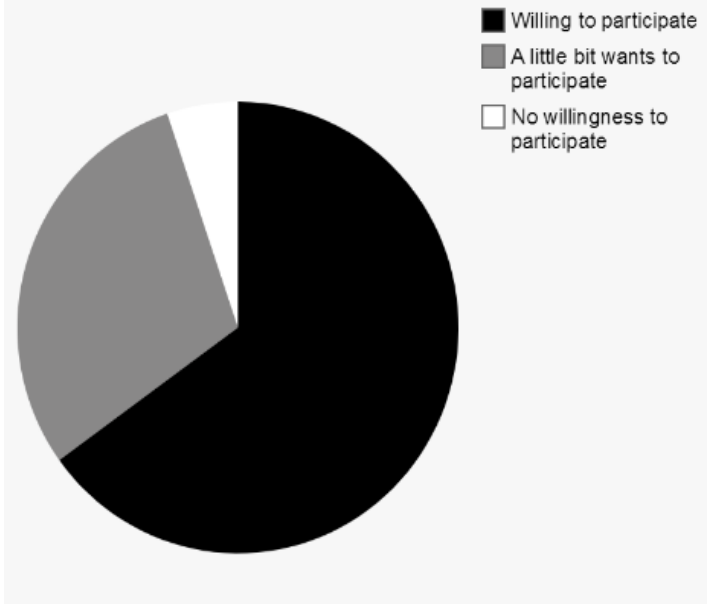

Figure 3. Willingness of the respondents to participate in decision-making 


\subsection{Problems of Relocated Residents}

The results of the survey show that the residents who have been relocated are not particularly satisfied with their current situation. The main problems are as follows:

\subsubsection{Poor satisfaction with placement compensation}

More than half of the relocated residents were dissatisfied or very dissatisfied with the compensation for the relocation. The reasons for the general dissatisfaction of the villagers included the following:

Firstly, the government mainly adopts a one-time compensation strategy, and they pay little attention to the residents' long-term livelihood. Lack of education and long-term financial planning, the residents' life sunk into difficulties after the compensation was quickly squandered.

Secondly, although the relevant departments actively coordinated the allocation of more than $1000 \mathrm{mu}$ of resettlement land, and started the resettlement area construction project timely, the villagers generally believe that the resettlement area north of the high speed around the city is too far away from the original village site, resulting in the feeling of being estranged from the site.

\subsubsection{Reduced living standards}

$77 \%$ of the relocated people believe that the application for the Han Chang'an city site, including the movement, has reduced their standard of living.

The displaced villagers lost the land on which they depended and had fewer other special skills. Coupled with a generally low educational background (see figure 4), which made it difficult to find an ideal job and lost a stable source of income (more than 65 per cent of respondents thought their income was lower after moving). These residents believe that they still have deep feelings for Han Chang'an city site. But the Special Administrative Committee seldom hires the relocated villagers to participate in the protection and construction, which hurts their feelings.

\subsubsection{Villagers feel worthless for self-sacrifice}

After the villagers had expected to move out of the site, the government would use the original land for large-scale tourism development to bring benefits to the surrounding people, but after years of work, they found that most of the land they had been expropriated was still "idle ". In fact, at present, the use of the relocation of the Weiyang Palace site is mostly based on the original appearance and logo display. This way of display is mainly aimed at professionals and enthusiasts, not for ordinary people lack understanding of this. The villagers generally believed that the land had become a so-called "wasteland " and their own sacrifice for the protection was not worth.

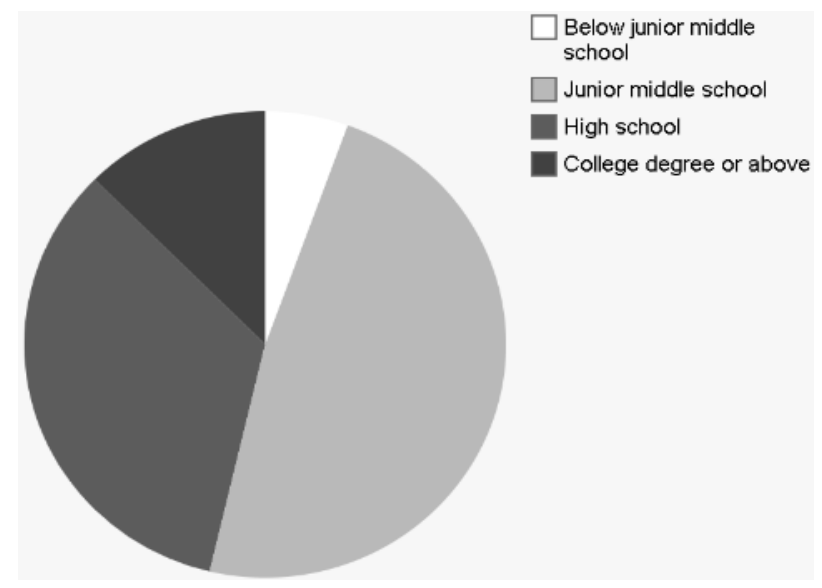

Figure 4. Educational background of relocated residents

\section{SOLUTIONS}

\subsection{Compensation for the Relocated Residents}

Judging from the actual situation of the investigation, the villagers of the site area had been restricted by the policy of heritage protection for a long time before the relocation, and made great sacrifices in order to take into account the overall situation of the protection of the site. The relevant departments cannot ignore their subsequent development problems because the relocated residents do not live in the site area. If the people who have lost their native land cannot be properly settled, it will not only lead to social contradictions, but also undermine the enthusiasm of the residents who still live in the site area to participate in the protection and development of the site. To effectively address the remaining issues, the following should be done: 
First of all, the remaining problems of levy and relocation compensation should be solved in time, and the relevant government departments should promptly implement all the compensation funds in place and arrange for the payment of transitional expenses in a timely manner. Relevant departments should hold financial management knowledge lectures for relocated villagers, guide villagers to do a good job of income and expenditure planning, make rational investment, and change the previous one-time "buyout" compensation practice, so as to realize the sustainable development of the villagers' own economy.

Secondly, as residents move out of the site area, they lost their land and lack of other living skills, which make it difficult for them to find an ideal job. Therefore, as far as possible, the management should arrange for such residents to undertake some basic work with low technical requirements and academic qualifications in the site area, such as: garden hygiene, security inspection, etc., and set up work training to broaden their employment opportunities.

\subsection{Properly Settle Residents in the Area, Improving Environment, and Infrastructure}

The survey showed that most of the residents still living in the site said they were reluctant to leave their homeland. And from the current actual situation, the huge cost of the requisition and relocation work has left a lot of problems. Furthermore, it is not likely or necessary to move all the residents.

When it is not suitable for relocation, some village which have not yet found the remains of the pressure-bearing sites could be remained. Infrastructure construction should be forbidden. For the villages that occupy only part of the ruins of the pressure site, only some residents who occupy the ruins directly can be moved out, and the remaining retained parts can be reformed according to the style of the Han Dynasty residence. Some villages with a small number of large areas occupying important sites should draw lessons from relevant experience and lessons, draw up a long-term and reasonable compensation policy by extensively soliciting public opinion, and gradually guide villagers to participate in the work of requisition and relocation voluntarily.

\subsection{Improving the Management to Promote Villagers' Participation}

Cultural heritage protection and management are people-oriented, so the needs of the public in the site area can not be ignored, and the degree of successful participation in decision-making in the site area will also affect the protection of the site on a large level.

According to the survey, more than 80 percent of the residents surveyed said the authorities had never consulted their views on the policy and planning for the protection and development of the site.

Therefore, it is very important to implement the corresponding policies and measures to promote the participation of the people in the protection and development of the site. Specifically, the following two areas should be achieved.

First of all, the residents should participate in making decisions. Based on the original villager's cultural protection, the non-governmental power could be strengthened. Establish the township virtuous workstation and coordinate the contradiction between the site and the residents. Expand the formation of the mass autonomous organization and stimulate the participation enthusiasm of the ordinary residents. Before formulating planning measures for major conservation and utilization, information briefings should be held in advance to collect the views of public. At the same time, face to face or phone call interviews should be made frequently. It is effective to hold unofficial seminars and empower villagers to independently formulate village rules for the protection of sites.

Secondly, it is necessary to ensure the effectiveness of residents' participation. The residents of the site area are mostly ordinary farmers, although they have participation enthusiasm, their suggestions always are neglected because lack of professional knowledge. Therefore, the effectiveness of villigers' participation is very low. Experts and scholars can be invited to improve the participation ability of the residents. At the same time, a planning audit team can be set up. Moreover, It is wise to coordinate the relevant suggestions of the villagers and establish a feedback system to ensure the effectiveness of the participation of the public.

\subsection{Strengthen Publicity and Education to Raise Residents' Awareness of Protection}

The fundamental to the protection of the site lies in raising the people's awareness of protection. Only when people realize the value of the site, they could devote themselves to protect the site[12].

However, according to the present survey, more than half of the residents believe that they have nothing to do with the site protection or have little to do with it, and the relevant departments rarely carry out targeted publicity and education work in this area. Therefore, it is necessary to strengthen the education and publicity of the residents in this region.

By means of display boards, leaflets, banners, newspapers, magazines and television media, the Special Administrative Region shall organize regular publicity activities related to the protection of the heritage. Through organizing villagers to visit the site to promote their understanding. Furthermore, Local education authorities could cooperate with the local academic and research institutions to compile local teaching materials, which should involve the content of history and introduction of Han Chang'an City-site. Cultivate the residents' feelings 
and identities of the sites in the original works so that they can understand the Han Chang'an City ruins and love the Han Chang' an City ruins, and then actively participate in the protection and development of the Han Chang'an City ruins.

\subsection{Promoting Tourism Development and Increasing the Income of Residents}

The above research shows that the residents of the site are not satisfied with the current development and utilization of the site. The majority of residents only consider their own point of view, thus the views are inevitably some one-sided. Moreover, the relevant departments should also actively respond to the needs of the public and accelerate the rational use of the site, with a view to promoting regional sustainable development at an early date.

The relevant departments should innovate the means of site display and utilization based on strictly protecting Han Chang'an City site. The process of exploration and excavation could be showed to the public. Experts and scholars could be invited to teach the traditional ideology, culture and literature art of the Han Dynasty. Moreover, Heritage protection and utilization could be combined with public life, leisure, physical exercise, create small-scale city square, green space and other people's livelihood projects. It can transform the original residence into Han cultural and creative courtyard, provide local artists with employment or living opportunities, create unique cultural tourism souvenirs while also making art and community development closely integrated[13]. In addition, the Han culture exhibition area can be established from the way of museum settlement, and the charm of Han culture can be displayed from different aspects. For example, the villages have not been relocated can be transformed into characteristic catering service area, the Han-style food can be provided to tourists. The new Science and Technology Park of Han Dynasty can be built to show the astronomical and geographical instruments such as Huntianyi(celestial globe) and ground-moving instrument, and demonstrate their working principle and usage method. The Han Dynasty military history museum can be established as the core of Han Chang'an Wuku site, with emphasis on displaying the cultural relics such as the ruins of Wuku(armory) and its unearthed weapons, and so on. The scene of ancient war can be reproduced by high-tech means. The carriage and ox cart commonly used in Han Dynasty can be used as the means of transportation in the site area. At the same time, combined with the newly excavated Weihe bridge and ancient ship relics, we can build a museum to display the transportation achievements of the Han Dynasty.

\subsection{Protection and Display of Intangible Cultural Heritage}

Han Chang'an City site contains not only extensive and profound Chinese culture, but also intangible cultural heritage such as traditional folk customs left over from various villages in the region. However, in recent years, due to the change of social structure and the increasing of foreign population, many villages and towns have been impacted by urbanization and foreign consumption culture.

Therefore, it is necessary to strengthen the investigation of the folk customs of the villages in the district (including the villages that have been demolished) as well as the collection and arrangement of the village history. At the same time, the intangible cultural heritage itself has historical, artistic, entertainment, education and other values, which is a good tourist viewing resource[14]. Therefore, through establishing the village historical memorial and folk museum, showing its long-standing way of life and traditional customs, visitors can deeply feel the evolving long history and folk customs.

In addition, we should support the development of cultural and creative industries in the site area, build a bridge between the residents and the enterprises, create more employment opportunities while developing original cultural products with Chinese characteristics, so as to promote the harmonious symbiosis between the site and the residents.

\section{CONCLUSION}

As one of the World Heritages, a large number of villages were located in the Han Chang'an City. Residents are the carrier of cultural heritage inheritance, and a sustainable development of the site could not be separated from the residents in this area. Through investigation of the residents living in the site and the residents moving out because of World Heritage nomination process, it shows that the relationship between the site and its residents is unexpected weak. This situation may be caused by low income, poor infrastructure, nasty environment and so on. Furthermore, the residents who moved out are also not satisfied with their living condition. Therefore, this article further proposes some improved measures. Firstly, we should solve the remaining problems of the residents who have moved out and ease the contradictions between the existing residents and the sites. Secondly, supporting the participation of the residents and social autonomous organizations in the management of the sites. Moreover, improving the environment and infrastructure in this area as well as strengthen publicity and education. In addition, promoting the development and utilization of the material and intangible cultural heritage. Finally, easing the conflict between the protection of cultural relics and social development in the sites.

\section{ACKNOWLEDGMENT}

This article is funded by the National Social Science Foundation's major project," Construction of Historical Geographic Information System of the Silk Road"(Project No. 14ZDB031). 


\section{REFERENCES}

[1]Zhang Zuqun, Chen Wenliang, Zhao Rong, Quan Dongji, and Wang Jianxin, "Factors of destruction in the protection of the great ruins: the case and reflection of Han Chang'an City, " Architectural Knowledge, vol. 2, 2005, pp. 5-8. (In Chinese)

[2]Quan Dongji, and Huo Xiaoping, “A preliminary study on the sustainable development of the great site conservation and tourism industry: Han Chang'an City conservation and utilization plan, " Journal of Northwest Institute of Architectural Engineering (Natural Science Edition), vol. 4, 2001, pp. 65-69. (In Chinese)

[3]Fan Haiqiang, and Quan Dongj, "Study on the characteristics of the great site and the mode of conservation and utilization: Taking the Han Chang'an City site as an example," Journal of Architectural Science and Technology University of Xi'an (Social Sciences Edition), vol. 4, 2005, pp. 142-146. (In Chinese) DOI: 10. 16348/j. cnki. cn61-1336/c. 2005. 04. 028

[4]Chen Whengliang, and Yang Lei, “A preliminary study on the destruction of residents in the protection of large sites:a comparative analysis based on the protection attitude of residents in the site area, "Journal of Northwest University (Natural Science Edition), vol. 41, 2011, pp. 887-892. (In Chinese) DOI: 10. 16152/j. cnki. xdxbzr. 2011. 05. 024

[5]Zhang Hong, "A study on the relocation of settlements in the protection of the great site, " Journal of Shangrao Normal College, vol. 29, 2009, pp. 58-64. (In Chinese)

[6]Institute of Archaeology, Chinese Academy of Social Sciences ed., Chinese Archaeology (Qin Han Volume), Beijing: China Social Sciences Press, 2010, pp. 174-179. (In Chinese)

[7]Xi'an Municipal Bureau of Cultural Relics, Xi' an Han Chang'an City Site Preservation Institute, Xi' an
Cultural Relics Conservation and Restoration Center, ed. , Han Chang'an City Site Protection, Beijing: Cultural Relics Press, 2012, pp. 21-27. (In Chinese)

[8]Xi'an Municipal Bureau of Cultural Relics, Xi' an Han Chang'an City Site Preservation Institute, Xi' an Ancient Construction Engineering Company, ed. , Towards the World: The Road to Application for the ruins of the Weiyang Palace in the Western Han Dynasty, Beijing: Cultural Relics Press, 2014, pp. 149-150. (In Chinese)

[9]Xue Yutong, The train of thought and reflection on the sustainable development of the Weiyang Palace site in the posthumous period, Master's degree thesis of Northwest University, Xi'an, 2015(In Chinese)

[10]Zhang Feng, A study of the agricultural landscape evolution guidance model in the conservation of Han Chang'an City, Xi'an, Master's degree thesis of Architectural Science and Technology University of Xi'an, Xi'an, 2009(In Chinese)

[11]Liu Kewei, and Niu Dong, "The current situation, problems and countermeasures for the protection, development and utilization of the Han Chang'an City site, " Economic Geography, vol. 5, 1999, pp. 110-112+117. (In Chinese)

[12]Wang Chunyang, and Li Wenjun, "What are the social responsibilities of the heritage tourist destination, " Resources and Environment in Arid Areas, vol. 32, 2018, pp. 191-196. (In Chinese) DOI: 10. 13448/j. cnki. jalre. 2018. 257

[13]Zhang Zhongxin, and Li Xiao, "An analysis of the function evolution of cultural and creative park," Economic Research Journal, vol. 24, 2012, pp. 185-187. (In Chinese)

[14]Zhang Yijia, and Song Junhua, "The protection of intangible cultural heritage in Wuzhen from the perspective of tourism development, " Cultural Heritage, vol. 6, 2014, pp. 151-156. (In Chinese) 